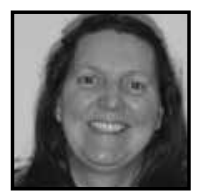

\title{
Using Brain Research and the Experience of Knitting Socks in Teacher Education
}

\author{
Zabe MacEachren, Queen's University
}

\section{ABSTRACT}

This article is a self-study of the experience of introducing sock knitting as a course assignment for teacher candidates. The idea originated from a personal desire to easily turn a sock heel while dealing with dementia in an aging parent who once knit well. The adaptations this assignment have undergone are explained with regards to a personal ongoing study of brain research, reflections about teaching knitting, and students' comments about the challenges of learning to knit socks.

\section{Introduction}

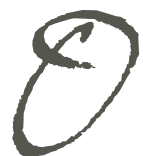

ver a period of approximately two years, three seemingly unrelated events led me to create a teacher education course assignment centred upon knitting a pair of socks. Firstly, I was reminded of the emphasis Waldorf education places on knitting while attending the Tri-fold Applied Handwork Conference where I observed that most fellow attendees knitted as they listened to presentations. The curriculum that introduces knitting in kindergarten was explained, as was the reason that socks are knit in grade five. Samples of children's knitting were used to discuss the developmental needs of the child. In presentations, the founder of Waldorf education, Rudolf Steiner, was referred to, and his idea that "knitting is cosmic thinking" was emphasized. I returned home determined to find and complete my second pair of socks, which I had started knitting a decade earlier.

Trying to turn a heel was the second event that led me to consider knitting as an educational activity worthy of teacher candidates' undertaking. My frustration 
originated from my need to constantly count stitches and pay attention to tedious directions. In most other craft work, I usually catch on quickly, grasp the fundamental concepts, and begin adapting so I can create my own designs. I had already knit numerous sweaters, hats, and mitts with ease. My PhD dissertation involved examining handwork and is entitled "Craftmaking: A Pedagogy for Environmental Awareness" (MacEachren, 2001), yet I was not able to knit socks with ease. I was particularly bothered by the idea that I needed to follow a pattern when my grandmother's generation had not and they were far less schooled than me. My frustration led me to begin to deconstruct the challenges I was experiencing.

The third event, sadly, resulted from trying to understand my mother's Alzheimer's disease. I found myself explaining to her how to complete simple puzzles and practice memory games. This led me to examine the reasoning skills required to complete various types of activities. Witnessing my mother's deteriorating knitting ability, which resulted from no longer being able to follow directions for sweaters with fancy cable stitches and colourful designs, led me to wonder not just why she was losing her cognitive ability, but how had she learned to knit in the first place. It struck me that her ability to knit elaborate sweaters had always been based upon her dutiful conditioning of following line-by-line directions. In contrast, my craft interest was based upon dealing with problems of design and mastering the underlying concepts: in knitting socks, it was to understand the basis involved in making a heel. I wanted to reiterate the practice early knitters had gone through when they invented a way to turn a ninety-degree angle in a knitted tube shape. I shared these thoughts about my mother and my sock endeavour with a colleague who was a master knitter. She, too, found the ideas and connections captivating as she could not remember a time when she had depended upon a pattern. Her main area of research was critical theory. During our dialogue, she mentioned the work of Jean Anyon (1992), whose research explored how teachers in different socioeconomic neighbourhoods taught differently: teachers in lower economic neighbourhoods emphasized rote learning and seldom taught problem-solving skills. I continued to be puzzled about the connection between memory and problem solving versus rote learning.

Throughout these events, I had conversations with colleagues concerning our students' learning patterns. Initially my intrigue was focused upon each generation's learning styles. Then I recognized that the proliferation in technology was influencing the way a person learned. In the back of my thoughts were the ideas I had acquired from taking a one-day Brain Gym workshop and from reading Carla Hannaford's book Smart Moves (2005). Hannaford's ideas became part of one of my classes where I provided the rationale and explanation for why the complex 
movements involved in activities such as climbing developed a person's thinking skills. My explanations were stated in general ways and avoided all the neurological terms Hannaford uses.

As these seemingly unrelated activities had been occurring, I had proposed to teach a new course, had received acceptance, and so was now beginning to plan my classes. I was seeking experiential activities and assignments that could highlight integration across subject silos. By then I had completed knitting my socks. My new understanding of socks had originated from long conversations at many wool stores with staff who seemed intrigued by my questions about knitting directions and my ideas connecting Alzheimer's disease with design work. As well I had purchased various books in order to compare directions as I sought clear descriptions and illustrations. As I knit I also reflected. During these introspective moments, I felt as if I could almost feel new neural networks forming as my comprehension grew. I became quite confident that I could knit socks now for any size foot by depending only on the concepts I held in my brain; I had no need for a pattern as I understood the essential elements of sock and was adept at problem solving and making changes. As I concentrated and challenged myself to understand socks as a concept, I noted how problem solving and deep thinking seemed both invigorating and exhausting. Time passed quickly and without notice. In "eureka" moments of understanding, I felt as if I were exercising my neural network of gray matter. One day I started considering all the ways I could integrate "learning" if I required my students to knit socks as an assignment.

Knitting my own socks is one thing, but the challenges involved in teaching a classroom of teacher candidates to knit socks led to many more questions concerning the best way to teach such a complex activity. I experimented with creating a paper cutout of a sock and writing directions on it. I envisioned students assembling sequenced paper sections in order to be guided through the knitting process. Each part could be taped to the next part until a three-dimensional paper sock was assembled and served as a guide through the knitting process. It took me numerous attempts to actually make my envisioned sock model. Craft work seems to have an additional rigor to it as ideas cannot just be conceived and illustrated as in visual art; instead craft work requires knowledge to be demonstrated through the process of creating something that fulfills a function. I like the challenge of working in designs that require moving with relative ease back and forth between two to three dimensions, between paper and concrete form. I knew that many novice teachers lack the confidence to teach many math-related topics, such as volume and surface area, so I wondered if my paper cutout idea would aid or frustrate their comprehension. All of 
these ideas came together as I seriously considered whether knitting socks would be a suitable course assignment and would allow me to make subject connections. As an outdoor educator, I consider wool socks a necessary piece of outdoor equipment, and my first publication addressed the importance of socks to environmental education (MacEachren, 1990). I liked the idea that socks were common to students, but that few would know anything about their history or creation.

\section{Course Parameters}

The course I taught had the usual parameters that most university courses contain. My classes were scheduled for twice a week over just one term. This condensed format provided little time for me to introduce knitting skills and for students to complete their homework. In fact, many students required two weekends before even being able to visit a store to purchase their knitting supplies. As this assignment was weighted less than other assignments, knitting homework was not a high priority in their busy lives. Classes were two hours and twenty minutes long, with approximately 10-30 minutes devoted in each class to instruction regarding sock knitting.

Providing knitting instruction in each class was not easy. I struggled throughout the course to become comfortable with the course timing as it differed from other courses that I was teaching. I stayed late after many classes to provide individual instruction and encouragement for students who wanted it. The amount of class time I provided to students to complete assignments was generous, and many students tended to work on their knitting during this time, when guidance was nearby; they preferred to complete small group assignments after class and through email correspondence. Our Faculty of Education only requires an Honour, Pass, or Fail grade, so grades do not motivate students to complete tasks on time. I had students complete a free-write on this knitting assignment during the course's second-last class, and these personal reflections were used to determine the assignments' success and any changes I should make.

\section{Knitting Instruction}

During the first class, I explained the assignment and ended the class with an experiential activity that explored twisting fibre into rope: small groups were to 
make a thick rope out of paper towels that would be tested for strength. As students twisted fibres, they were to associate their action with as many rope- and yarn-based metaphors as they could brainstorm. It seemed appropriate to start the knitting activity by exploring fibre and the twisting motions involved in yarn production.

In the second class, I focused on their equipment needs and introduced learning to knit. I raised questions to spark a brief discussion concerning the social and environmental impact involved in consumer practices, even something as seemingly insignificant as obtaining knitting materials: students were asked to think about whether they would want to handle wool or synthetic material and whether it was better for the environment to purchase metal needles or wooden needles made in China. At this time, so they could begin practising while they purchased their own supplies, everyone received yarn, two wooden skewers (sanded to a dull smooth point), and a set of directions. Every set of direction came from a different source so each was different: some had illustrations and photographs while others did not, yet all explained the casting on, knit, and purl stitches. Students were instructed to learn themselves using only their own set of directions and to mark up their copies with notes concerning all the insufficiencies of their particular set of directions and/ or illustrations. After trying to master the stitches for at least a half-hour with just the directions provided to them could they then, if they so desired, try to find a better source for learning. In the following class, a lively discussion ensued concerning what made for the best set of directions and how any images provided aided comprehension or still could be improved. Class time was then provided for students to share what they had learned about the process of learning and to teach one another until everyone could cast on, knit, and purl.

Over the next two weeks students continued to practice knitting and purchase their equipment. They began to create an appropriate-sized pattern by knitting a swatch in order to determine how many stitches needed to be cast on. Along the way, to encourage my students, I shared personal stories of my own frustration having to knit by counting and following row-by-row instructions. I shared stories from Jean Anyon's research and inquired why they thought teachers hesitate to offer their students problem-solving experiences, instead frequently using teaching procedures based upon rote learning. I wore the sweaters my mother had knit me, and I spoke of her diminishing ability to comprehend directions and difficulty doing brain puzzles; I asked if anyone had ever had to deal with seniors, especially in light of Canada's aging demographics and that they might consider working in this area. They were asked to consider the role of lifelong learning in creating healthy individuals of all ages. I shared the pedagogical ideas supporting Waldorf schools teaching kindergarten 
students to knit and grade five students to knit socks. I asked them to think about how they learn difficult tasks and how any previous learning challenges relate to their experience of knitting socks.

As the students' learning stages became more staggered, I realized the parameters and stress they were encountering. I constantly adapted what I could do in class to help them and always made myself available afterwards for questions. Slowly, I started to worry about the success of this assignment; this concern peaked around the time I provided them with my paper cutout tactics, which had led me to so confidently understand how to turn a heel. The students seemed slow to engage in this activity. They hesitated to answer questions and share any thoughts concerning their understanding of knitting socks. I tried to determine why they seemed reluctant to engage in this problem: did they lack experience using three-dimensional shapes? Were they just tired, stressed, and preoccupied with other assignments? Had they been in classes sitting all day, no longer able to concentrate? They did tape together the paper cutout into a sock form but seemed uninterested in making any connection to the ingenuity early knitters exhibited as they problem solved how to make a heel shape. I would later come to understand that I had introduced this activity too soon: most students were frustrated because they were just seeking more time to repeat the basic knitting procedures rather than moving on to the more complex challenge.

I continued on, trying to accommodate students at various stages of task completion. By manipulating and designing my paper sock pattern, I had solidified in myself the ability to recognize errors and explain things in a variety of ways, and this was a useful skill. I used large needles so it was easier for people to watch my demonstrations. I knitted more socks, leaving them unfinished at various stages of turning a heel so the students could handle these samples to aid their comprehension. I recognized all the problem-solving and critical-thinking skills embedded in this activity, but I wondered if teacher candidates were also able to do so.

The students' class attempts to turn a heel were then disrupted by their twomonth departure from campus to complete their teaching practicum. Everyone left with my paper set of directions, and they would now have to teach themselves or find a knitting mentor. Realistically, I knew that most students would not have a teaching schedule that would allow them to complete their first heel. I realized that I might need to lower my expectations for this project and just aim for students to complete one sock with a strong desire to finish the other after graduating. It was during this period that I found the time to finally read some of the books I had been gathering about brain research, and I frequently applied these new ideas to my reflection of 
what had been happening in this knitting assignment.

When the students returned from their practicum for the final two weeks of classes, I was pleased with the way they focused on completing their socks. Again, I stayed late after classes to provide individual instruction to all who desired it. Over the practicum, a few students had turned to the Internet, friends, mothers, or grandmothers for instructions about completing their sock; a couple of students had mustered through, problem solving with many resources as I had done to try and figure things out. During the last week of classes, students were expected to show me their completed sock(s), or at least what they had been able to accomplish, and this, along with their other assignments, was used to determine an Honours or Pass grade. During the second-last class I had them reflect upon their success and what they had learned through the process of knitting socks by completing a free-write on their experience. During the free-write, I occasionally wrote a question on the board that they could respond to or not. The students' comments ${ }^{1}$ during this free-write are the sources of the quotes I use below.

Our final class was spent visiting a sheep farm on a nearby island. On the ferry ride over to the farm, I shared more stories and interesting lore about knitting. I wanted to end as I had begun, by emphasizing connectivity and how one thing can be unravelled into a long yarn of related ideas. The two stories specifically chosen for my few technology students involved knitting while riding on the back of a motorcycle and an incident involving using knitting to de-escalate road rage (Zimmerman, 2005). At the farm, students made many more connections: their questions concerned the meat industry, how waste water is dealt with, and the farmer's ethics concerning predator control. Driving home from the sheep farm, I had two thoughts: I recognized that the whole knitting experience was successful enough that I should try it again, and I should make direct connections to the brain research I had recently read. I had yet to find the time to read the students' free-write reflections, but when I did, they offered me insights on ways I could better make connections between this knitting activity and the way the brain works, ultimately aiming to improve teaching practices to better support learning.

\section{Assignment Evaluation}

I entered this knitting project with a strong curiosity but very limited understanding of brain research. I ended with a strong desire to continue learning how 
to effectively use this research to better my own and student teachers' teaching. My first year of using the sock-knitting assignment had been supported by very informal connections to a very limited understanding of the significant ways both my learning and my teaching could benefit from brain research. I had offered a few of Hannaford's ideas because I had used them briefly before to provide a rationale for climbing activities to outdoor educators. Now I recognized how I could have more effectively used the findings of brain research by examining, in detail, ideas such as what is involved in order to concentrate and what role repetition plays in memory as the students engaged in those aspects of learning through their knitting tasks.

The changes I plan to take in this knitting assignment were based upon my reflections completed after benefiting from reading about how the brain worked. The main change I will make is to combine it with a knitting journal that centres upon students correlating their knitting experience to the findings of brain research. The many journaling activities I now plan to introduce have been arranged into subsections that reflect some of Medina's principles outlined in his book, Brain Rules (2008). Because the journaling of the students' experience will take additional time, I have made two changes. I have eliminated another assignment from the course to place a greater emphasis on this one; also, I have requested and received permission to reschedule the course so that classes occur once a week for two terms. The changes I plan to make in this assignment relate to my understanding of how to effectively use and teach brain research in education. My rationale for the changes is explained below; the italic passages and identification numbers represent comments from different students' free-write assignments (GREB, Queens University).

\section{Movement and Concentration}

All of the brain research I have read emphasizes the important role of fitness for ensuring proper brain function [Hannaford (2005); Medina (2008); Ratey (2008); and ADEAR (2011)]. As a result of this new awareness, I have increased my own physical activity and am working on ways I can introduce short cardio-based activities in my classes to role model this important principle. My own reflection repeatedly has me aware of feeling more positive and thinking well on days I have exercised. I now seek ways to encourage teacher candidates to become aware of their own patterns that improve and hinder learning. In the final week of the course, I had a lengthy discussion with a student who had realized that she was not capable of teaching in a classroom because she had such a strong need to be physically active. As this was the same student who had shared that knitting had helped her concentrate in her large lecture hall classes, our conversation led to discussing the way schools and work 
environments could be improved by making accommodation for more physical movement. Knitting is not the kind of physical activity that increases our heart rate, but there might be something very important in keeping our hands a little active in order to aid concentration. Wilson's (1998) book "The Hand..." provides some understanding for the link between hand and brain development, but is limited in the extent it explains the necessity of movement whether in the hand or body for optimal brain functioning.

Hannaford (2005) was the only researcher I read who described the importance of small movements as well as aerobic-based exercise. She emphasized how even small movements can anchor thought: "Many of us have a distinct tendency to think better and more freely while engaged in a repetitive, low-concentration physical task" (p. 109). In describing the way the subtle movements involved in talking can anchor thinking, she also described how chewing gum and knitting can provide similar appropriate movements (without the noise of everyone talking). In my future classes, after outlining the importance of fitness and cardio activity in learning, I plan to share Hannaford's ideas with my students and ask them to note in their knitting journals when they find the subtle movements involved in knitting distract them or aid their concentration.

I also realized that knitting could be used to clarify the link between a person's ability to focus and uninterrupted concentration time. It was during this course that I first experienced many students using screen devices as I taught. As a teacher, I found it distracting but questioned whether I was being unfair because I did not mind students knitting as I lectured. I had explained to students what I consider to be the etiquette of knitting: they should only knit in class when they are so familiar with the skill that they seldom need to look at their hands, and they do not need to read directions, count, or ask a friend for help because this means they are off the task of listening. After reading Carr's (2010) chapter entitled The Juggler's Brain, I realized how different technology affects our brain. It can be argued that both knitting needles and screen devices offer low-concentration physical activity; however, today's screen devices are purposely programmed to offer distraction, to pull our thoughts away from tasks we should be focusing upon to instead think about replying to incoming emails, and notice what a flashing image or beep is about. In the future, I will ask students to compare their ability to concentrate on a lecture while knitting to that of having an open laptop in front of them. Their comparisons will be both discussed in class and recorded in their journals in the context of describing what type of activities they will allow their own students in the future to engage in while they are teaching. 


\section{Memory}

After reading students' descriptions concerning their frustration and their method of learning to knit socks, I realized that what they were expressing was a struggle to engage both short- and long-term memory skills. Many students wrote about their challenges to remember how to knit and purl between the time slots they devoted to knitting.

- Ineed clear directions, lots of pictures, and repetition. (6)

- Repetition is key in learning a new skill or even a piece of information. (7)

- I would try and fail until I got it right. Once I learn a skill on my own, I know how to do it for life; my hands remember long after my brain has forgotten the instructions. (4)

- I will try to remember the feeling of frustration of not quite "getting" it and the persistence needed to finish the project. (17)

- I hope to finish my one sock and then begin knitting its mate (I hope hope hope I can recall all the first steps to make the second sock). (7)

After reading Medina's (2008) two principles concerning "remember to repeat" for long-term memory (p. 147) and "repeat to remember" for short-term memory (p. 119), the role of repeating and repetition in memory became clarified. I recognize the way I misinterpreted the students' initial struggle to remember as a disinterest in or reluctance to begin the assignment. To have students engage with the ideas of how memory works in the brain, I will build upon my early activity of having them evaluate the paper directions I gave them to learn the knit and purl stitches. In their journals, the students will extend this initial learning activity by recording directions that they find work as efficient memory aids between knitting time slots. Discussions concerning what make directions and illustrations effective, such as their clarity, conciseness and repeatability will be emphasized. By expecting them to create clear, concise notes to use in supporting their own memory, Medina's short two memory principles can be both evaluated and experienced in their knitting assignment. 


\section{Diversity in Learning}

As I learned how every brain is wired differently I realize that exploring the way different knitting descriptions cater to different students' learning styles is a useful way to emphasize that teachers should be capable of instructing in various manners. Teacher candidates made similar observations:

- I noticed that many people in this class were taking different approaches to learn to knit, and I found that really interesting. There is more than one style to teach/learn about any subject, task or idea. (16)

- I I used multiple methods to try and learn how to knit socks. .. (1)

- Ifound it interesting that no one person learned in the same way. Some were visual, oral, kinesthetic, etc. Knitting was a great experiment to show the different ways of learning. (17)

As I internalized Medina's rule, "All brains are wired differently" (p. 70), I realized I could plan to have teacher candidates compare the directions they found the most useful with those of their peers and note the differences in their journals. Understanding the role of repetition in building knowledge, being able to prioritize fundamental concepts so clutter does not interfere with retaining key factors, and benefiting from the way understanding is best achieved through various channels with different people are all key concepts for teachers to hold.

\section{Sleep, Nutrition, and Stress Management}

The importance of getting adequate sleep, eating well, and reducing chronic stress in one's life are frequently cited in the brain research as critical aspects required for effective brain performance (Medina, 2008; Ratey, 2008). Teachers can be made aware of these principles, but they have little control over how they influence their students' lives. My students commented upon the various levels of stress they engaged in throughout this assignment and described how and why the stress involved in knitting changed:

- At first I was frustrated, but once I figured it out, I found it very relaxing. I am a very high energy person who never stops thinking and stresses out a lot, so I find knitting to be very relaxing. (12)

- When I got into a good flow and knew what I was doing it was relaxing and a stress reliever, yet at other times it was stressful and frustrating. (18)

- What can I say about knitting? It was such an interesting experience. I was dreading [knitting] when we were first told about the assignment. I had no 
interest in really learning to knit. However, ... I found the skill quite relaxing. (16)

- I I feel like I have failed this assignment. However, in ways I have not as I am not giving up. I will persevere until my socks are complete. I just need some more downtime and some more guidance. (10)

After sharing information on factors that affect brain functioning, such as nutrition, sleep, and stress, I plan for teacher candidates to note in their journal any correlation they observe between such factors and their knitting anxiety levels. I would like them to clearly understand why an activity like knitting can shift between being stressful and relaxing. It is important for teachers to understand how chronic stress influences thinking ability (both positively and negatively) and know about useful strategies for dealing with it in their own and their students' lives. Teacher candidates will be asked to reflect in their journal upon how these ideas will influence the challenges they place on others in their teaching.

\section{Hand-to-Brain Connection}

The physicality of knitting and the mental challenges of moving between two- and three-dimensional forms were the original reasons I thought this assignment could be useful at a teacher education level. Below is an example of one student's revelation about learning:

- I'm still a very kinetic learner. I learn through doing. I need to pick up the materials and somewhat bulldoze my way through it [the task]. Following instructions both irritates and bores me when learning a new skill. (4)

Next year, I will outline some of the theories pertaining to the role the hand may have played in brain and human development. I aim to provide teacher candidates with more reasons for providing hands-on activities in the assignments they offer to their students. To highlight some of these ideas I will combine Connolly's (2001) (as cited in Hannaford, 2005) and Wilson's (1998) work with the flint knapping skills that Burke and Ornstein (1997) outline that led to the development of language. In one class I will lead an activity where students try to convey a simple task to another person without using words. Through this task they can begin to comprehend how language increases our ability to convey complex skill and leads to logic development. They will then be asked to respond in their journals to this activity and the ideas presented in class that pertain to the importance of conveying hand skill in human brain development. 


\section{Vision}

One of the reasons few teachers will embark on teaching a craft is because they intuitively know it is best taught in one-on-one relationships because the learner must see the instructor's hand movements. Because providing close-ups are difficult in large classrooms, transmitting craft work that involves students observing fine motor skills is rare in school curricula. New technologies may alleviate that problem; for example, a student in the class told me about some equipment that would enlarge my hand movements onto a real-time screen. Next year, I plan to experiment with using this machine when I give directions so that more students will be able to clearly see what I am doing as I describe my actions. Many students commented upon the importance of the senses, especially vision, in their learning process:

- I I am not a tactile learner but tend to rely on visual and auditory information.... I found it so helpful to have my peers walk me through the steps both visually and by talking to me. (1)

- I have learned that I need very detailed and illustrated instructions to help me knit socks. I have watched a lot of YouTube videos during this process and found that they helped me a lot with technique. I have always known that I was a visual learner, and this process just solidified that for me. (9)

- Knitting has changed my ideas of teaching in a number of ways. First, I learned a lot about how I learn: I am very hands-on and need to be shown how to do something, or have very visual instructions with good descriptions. (16)

In describing how vision trumps other senses Medina (2008) states: "Educators should know how pictures transfer information" (p. 237). He describes how to effectively use images in presentations to emphasize points. In the future, I plan to demonstrate some of Medina's ideas through PowerPoint slides I design, which will be followed by students creating slides for their journals.

To encourage critical thinking I also will provide students with some of Turkle's (2009) ideas about how the ubiquitous use of PowerPoint presentations in schools has affected youths' ability to think. She discusses how PowerPoint slides are biased towards the use of bullets to convey ideas, which hinders the practice of following long passages of logic as required in reading books. I will ask my students in their journals to comment upon how they can benefit from both Turkle's criticism of and Medina's support for PowerPoint slides in their own teaching. I will then suggest that students question how experiencing the knitting of a sock is like watching a slowly moving video and ask them to discuss to what degree slow movement and time to think are required to develop critical thinking skills. 


\section{Brains Desire Learning}

The way the human brain has evolved has led us to be natural explorers capable of adapting to change (Medina, 2008). Students' comments reflected this ability as they recognized knitting a sock could be an adventure in learning. Their natural desire to learn as encountered through this activity of knitting socks was initially accompanied by both negative and positive reactions, as expressed below:

- L Learning something brand new is scary and made me feel "young" and "weak." But in the moments that I thought I was getting somewhere, I was proud and empowered. (10)

- I look forward to the satisfaction of having my own "home-made" socks and I hope to learn how to knit other things in the future. I loved this assignment!!

- ... and seeing what I was creating was exciting. (16)

- I I knitted for almost 13 hours, No Joke!... In all this time, I only managed to master the heel flap and the turning of the heel on one sock! However, the enjoyment and determination to master certain parts of the sock kept me motivated. It was the fastest 13 hours I have experienced in a long time. (15)

The sense of intrigue in learning a new skill that can snowball into hours of time passing quickly can be broken down into the concepts brain researchers use to describe how learning and problem solving are "hard wired" into us. In next year's course, I will provide some context for the way this hard wiring works by describing the existence of mirror neurons that are scattered across the brain and why imitation and role modeling is such an effective teaching method. As I present such ideas to my students, I will ask them to reflect upon their own teaching practices. What type of learning activity can be so engaging that it makes time pass quickly? How will understanding the malleability of the brain influence their engagement in lifelong learning? One of the current students already values this engagement; she wrote:

- I now recognize, however, the importance of learning something new even when you're the "teacher." It's important to challenge ourselves everyday until the day we die. (10)

To initiate a conversation on these ideas, I may collect written passages about crafts and other activities that describe, in detail, a passion for learning. After sharing these descriptions, I will then ask students how as teachers they will spark an interest in learning in their own students. 


\section{Conclusion}

Whereas my overall interest in craft work led me to complete my PhD, my specific desire to knit a sock with ease led me to brain research. This case study was about the way I used the activity of knitting socks along with a limited but growing understanding of brain research to improve my own teaching and, hopefully, that of the teacher candidates I work with. By encouraging students to continually reflect on, analyze, evaluate, and write about a sock-knitting experience, I aim to promote their use of recent findings in the area of brain research in their teaching careers. By sharing my own process of discovering the benefits of using brain research in one's work, I plan to have teacher candidates deconstruct the knitting process as they simultaneously knit socks; thereby becoming designers of educational practices that effectively use information pertaining to how the brain works.

\section{Notes}

1. I gratefully acknowledge the students and teacher candidates who provided me with permission to use their writing in my quotations.

\section{References}

ADEAR, Alzheimer's Disease Education \& Referral Center. Retrieved January 6, 2011, from http://www.nia.nih.gov/Alzheimers/Publi cations/CaringAD/default.htm

Anyon, J. (1992). Social class and the hidden curriculum of work. In Colombo, G. (Ed) Rereading America: cultural contexts for critical thinking and writing (pp. 521-540). Boston: St. Martin's.

Burke, J., \& Ornstein, R. (1997). The axemaker's gift. New York: Putnam Book.

Carr, N. (2010). The shallows: What the Internet is doing to our brains. New York: W. W. Norton \& Company.
Connolly, K. J. (2001). The psychobiology of the hand. New England Journal of Medicine, October 25.

Hannaford, C. (2005). Smart moves. Utah: Great River Books.

MacEachren, E. (2001). Craftmaking: A pedagogy for environmental awareness. (Unpublished doctoral dissertation). York University, Toronto.

MacEachren, Z. (1990). Prospect point. In Pathways, Council of Outdoor Educators of Ontario (1990), 28.

Medina, J. (2008). Brain rules. Seattle: Pear Press. 
Ratey, J. (2008). Spark: the revolutionary new science of exercise and the brain. New York: Little Brown and Company.

Turkle, S. (2009). Frontline Interview Sherry Turkle. Retrieved May 18, 2011, from http:// pbs.org/wgbh/pages/frontline/digitalna tion/interviews/turkle.html?utm_camp
Wilson, F. (1998). The hand, how its use shapes the brain, language, and human culture. New York: Pantheon Books.

Zimmermann, E. (2005). The opinionated knitter: Elizabeth Zimmermann newsletters 19581968. Pittsville, Wisconsin: Schoolhouse Press.

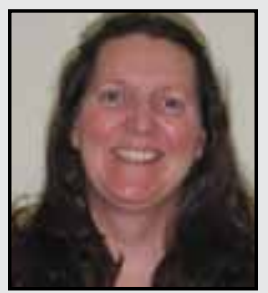

Zabe MacEachren is the coordinator of the Outdoor \& Experiential Education Program in the Faculty of Education at Queen's University, Kingston, Ontario, Canada. Her main area of research is connecting craft-making activities to environmental education. She has numerous publications in journals on this topic. Her current area of research focuses on bringing the Waldorf handwork curriculum and the practice of using hand tools in Forest Schools into the public school system. 